University of Nebraska - Lincoln

DigitalCommons@University of Nebraska - Lincoln

Publications from USDA-ARS / UNL Faculty

U.S. Department of Agriculture: Agricultural

Research Service, Lincoln, Nebraska

$11-1-1997$

Growing degree-days: one equation, two interpretations

Gregory S. McMaster

USDA-ARS, greg.mcmaster@ars.usda.gov

Wallace Wilhelm

University of Nebraska-Lincoln, wwilhelm1@unl.edu

Follow this and additional works at: https://digitalcommons.unl.edu/usdaarsfacpub

Part of the Agricultural Science Commons

McMaster, Gregory S. and Wilhelm, Wallace, "Growing degree-days: one equation, two interpretations" (1997). Publications from USDA-ARS / UNL Faculty. 83.

https://digitalcommons.unl.edu/usdaarsfacpub/83

This Article is brought to you for free and open access by the U.S. Department of Agriculture: Agricultural Research Service, Lincoln, Nebraska at DigitalCommons@University of Nebraska - Lincoln. It has been accepted for inclusion in Publications from USDA-ARS / UNL Faculty by an authorized administrator of DigitalCommons@University of Nebraska - Lincoln. 


\title{
Growing degree-days: one equation, two interpretations
}

\author{
Gregory S. McMaster ${ }^{\mathrm{a}, *}$, W.W. Wilhelm ${ }^{\mathrm{b}}$ \\ a USDA-ARS, Great Plains Systems Research, P.O. Box E, Fort Collins, CO 80522, USA \\ ${ }^{\mathrm{b}}$ USDA-ARS, Soil and Water Conservation Research, 119 Keim Hall, University of Nebraska, Lincoln, NE 68583-0934, USA
}

Received 24 January 1997; accepted 26 February 1997

\begin{abstract}
Heat units, expressed in growing degree-days (GDD), are frequently used to describe the timing of biological processes. The basic equation used is GDD $=\left[\left(T_{\mathrm{MAX}}+T_{\mathrm{MIN}}\right) / 2\right]-T_{\mathrm{BASE}}$, where $T_{\mathrm{MAX}}$ and $T_{\mathrm{MIN}}$ are daily maximum and minimum air temperature, respectively, and $T_{\mathrm{BASE}}$ is the base temperature. Two methods of interpreting this equation for calculating GDD are: (1) if the daily mean temperature is less than the base, it is set equal to the base temperature, or (2) if $T_{\text {MAX }}$ or $T_{\text {MIN }}<T_{\text {BASE }}$ they are reset equal to $T_{\mathrm{BASE}}$. The objective of this paper is to show the differences which can result from using these two methods to estimate GDD, and make researchers and practitioners aware of the need to report clearly which method was used in the calculations. Although percent difference between methods of calculation are dependent on $T_{\mathrm{MAx}}$ and $T_{\text {MIN }}$ data used to compute GDD, our comparisons have produced differences up to $83 \%$ when using a $0^{\circ} \mathrm{C}$ base for wheat (Triticum aestivum L.). Greater differences were found for corn (Zea mays L.) when using a base temperature of $10^{\circ} \mathrm{C}$. Differences between the methods occur if only $T_{\mathrm{MIN}}$ is less than $T_{\mathrm{BASE}}$, and then Method 1 accumulates fewer GDD than Method 2. When incorporating an upper threshold, as commonly done with corn, there was a greater difference between the two methods. Not recognizing the discrepancy between methods can result in confusion and add error in quantifying relationships between heat unit accumulation and timing of events in crop development and growth, particularly in crop simulation models. This paper demonstrates the need for authors to clearly communicate the method of calculating GDD so others can correctly interpret and apply reported results. (C) 1997 Published by Elsevier Science B.V.
\end{abstract}

Keywords: Corn; Growing degree-days; Timing of biological processes; Crop simulation model

\section{Introduction}

Since 1730 when Reaumur introduced the concept of heat units, or thermal time, many methods of calculating heat units have been used successfully in the agricultural sciences. Particularly in the areas of crop phenology and development, the concept of heat units, measured in growing degree-days (GDD, ${ }^{\circ} \mathrm{C}$-day), has vastly improved description and predic-

\footnotetext{
${ }^{*}$ Corresponding author. E-mail: greg@gpsr.colostate.edu
}

tion of phenological events compared to other approaches such as time of year or number of days (e.g., Cross and Zuber, 1972; Gilmore and Rogers, 1958; Klepper et al., 1984; McMaster, 1993; McMaster and Smika, 1988; Russelle et al., 1984).

The canonical form for calculating GDD is:

$\mathrm{GDD}=\left[\frac{\left(T_{\mathrm{MAX}}+T_{\mathrm{MIN}}\right)}{2}\right]-T_{\mathrm{BASE}}$

where $T_{\mathrm{MAX}}$ is the daily maximum air temperature, $T_{\mathrm{MIN}}$ is the daily minimum air temperature, and 
$T_{\mathrm{BASE}}$ is the temperature below which the process of interest does not progress. $T_{\mathrm{BASE}}$ varies among species and possibly cultivars, and likely varies with growth stage or process being considered (Wang, 1960). To simplify Eq. (1), the quantity $\left[\left(T_{\mathrm{MAX}}+\right.\right.$ $\left.T_{\mathrm{MIN}}\right) / 2$ ] is sometimes set equal to $T_{\mathrm{AVG}}$. The intent of Eq. (1) is to describe the heat energy received by the crop over a given time period (i.e., integrate the area under the diurnal temperature curve, sum the daily heat energy over an interval of time, and then relate the accumulation of heat energy to progress in development or growth processes).

Many modifications to enhance the biological meaning of Eq. (1) have been suggested such as (1) incorporating an upper temperature threshold (Gilmore and Rogers, 1958; McMaster and Smika, 1988; Wang, 1960), (2) converting to photothermal units by adding a photoperiod variable (Masle et al., 1989; Nuttonson, 1948), (3) using only the maximum or minimum temperature or portion of the day (Cross and Zuber, 1972; Masle et al., 1989), and (4) incorporating functions for other environmental factors that affect phenology or the process being considered (e.g., water, nutrients, light quality or quantity, $\mathrm{CO}_{2}$; McMaster et al., 1992b; Wilhelm and McMaster, 1995). Also, much effort has been directed toward improving the way Eq. (1) represents the integral of the diurnal temperature curve such as (1) calculating $T_{\mathrm{AVG}}$ using hourly temperatures (Cross and Zuber, 1972) or as a modified sine wave or other diurnal temperature patterns (Allen, 1976; Pruess, 1983; Zalom et al., 1983) and (2) correcting for variable observation times of $T_{\mathrm{MAX}}$ and $T_{\mathrm{MIN}}$ (DeGaetano and Knapp, 1993). While these efforts often improve the accuracy of predictions, many anomalies continue to exist that violate underlying assumptions. Obvious examples include weather fronts occuring during a day shifting maximum and minimum temperatures from typical times and changing the diurnal pattern significantly from the assumed pattern. For detailed review of the concept of GDD, see Arnold (1960), Pruess (1983), Wang (1960), and Zalom et al. (1983).

A number of scientists have tested the accuracy of various forms of the basic GDD equation (Eq. (1)) in predicting various growth and development processes in several species. For example, Perry et al. (1986) noted 14 variations of calculating GDD for cucumber (Cucumis sativus L.), Cross and Zuber (1972) discuss 22 methods, and Gilmore and Rogers (1958) examined 15 different methods of calculating GDD for corn.

Among all the methods of calculating GDD and its modifications, it was not until very recently that important differences in implementing Eq. (1) became apparent to us. Depending on the method of implementation, which as a general rule seems to vary depending on the crop, different values of GDD are calculated. In examining the literature and discussing this among scientists using GDD calculations on a regular basis, we realized that Eq. (1) is being implemented differently and users are unaware of this difference in implementation. This can be important in simulation models where values of GDD for duration of a process are estimated. If the method of calculating GDD is not the same in both the model and values used to parameterize the model, error is introduced. The same problem would apply to practitioners using GDD estimates calculated differently from how they calculate GDD.

The objectives of this paper are to describe the two implementations of calculating GDD from Eq. (1), what this means, and to stress the importance of clearly noting which method is being used when reporting GDD. Differences in implementation of Eq. (1) can also be a problem in many of the variations of the canonical equation defined by Perry et al. (1986), Cross and Zuber (1972), and others.

\section{Calculations}

Two interpretations of Eq. (1) are reported in the literature which differ in how the base temperature is incorporated into the equation.

\subsection{Method 1}

$\mathrm{GDD}=\left[\frac{\left(T_{\mathrm{MAX}}+T_{\mathrm{MIN}}\right)}{2}\right]-T_{\mathrm{BASE}}$

where if $\left[\left(T_{\mathrm{MAX}}+T_{\mathrm{MIN}}\right) / 2\right]<T_{\mathrm{BASE}}$, then $\left[\left(T_{\mathrm{MAX}}\right.\right.$ $\left.\left.+T_{\mathrm{MIN}}\right) / 2\right]=T_{\mathrm{BASE}}$. This method seems to be the most widespread method used for calculating GDD, particularly in simulation models (e.g., Davidson and 
Campbell, 1983; Gallagher, 1979; Goyne et al., 1977; Jefferies and Mackerron, 1987; Kirby, 1995; Mathan, 1989; Masle et al., 1989; McMaster and Smika, 1988; Narwal et al., 1986; Nield and Seeley, 1977). This method predominates among researchers and practitioners involved with small grain cereals such as wheat and barley (Hordeum vulgare L.).

\subsection{Method 2}

$\mathrm{GDD}=\left[\frac{\left(T_{\mathrm{MAX}}+T_{\mathrm{MIN}}\right)}{2}\right]-T_{\mathrm{BASE}}$

where if $T_{\mathrm{MAX}}<T_{\mathrm{BASE}}$, then $T_{\mathrm{MAX}}=T_{\mathrm{BASE}}$, and if $T_{\text {MIN }}<T_{\text {BASE}}$, then $T_{\text {MIN }}=T_{\text {BASE }}$. Sometimes a variation is comparing only $T_{\mathrm{MIN}}$ to $T_{\mathrm{BASE}}$. This is the most commonly used method in calculating GDD for corn, but is used for other crops as well (e.g., Baker et al., 1986; Bauer et al., 1988; Cutforth and Shaykewich, 1989; Edwardson and Watt, 1987; Ketring and Wheless, 1989; Masoni et al., 1990; Russelle et al., 1984; Swanson and Wilhelm, 1996; Tollenaar et al., 1979; Wilhelm et al., 1987, 1989). Occasionally, a combination of the two methods is used (e.g., Baker et al., 1986).

The important distinction between the two methods is when temperatures are compared to the base temperature. In Method 1, the comparison to $T_{\mathrm{BASE}}$ occurs after calculating $T_{\mathrm{AVG}}$, whereas in Method 2 the comparison to $T_{\mathrm{BASE}}$ is made before calculating $\frac{\left(T_{\mathrm{MAX}}+T_{\mathrm{MIN}}\right)}{2}$ by comparing $T_{\mathrm{MAX}}$ and $T_{\mathrm{MIN}}$ to $T_{\text {BASE }}$ individually.

When examining the literature, it is often difficult to ascertain which method was used. Based on our experience, and then discussing this with others, it appears that researchers assume incorrectly that all others apply Eq. (1) as they do. For example, in McMaster and Smika (1988) and Wilhelm et al. (1987, 1989), we calculated GDD as we thought correct (McMaster, Method 1; Wilhelm, Method 2), but did not clearly present the method used in the papers. When collaborating (McMaster and Wilhelm, 1997) we discovered this difference in implementing Eq. (1).

Once aware of the discrepancy in calculating GDD, we asked other scientists how they calculated GDD to determine if one of us was in error, and soon realized that there was no commonly agreed upon method. Examination of the literature (see examples cited above), confirmed this realization, yet we did not know if the discrepancy was important.

\section{Methods}

We used both methods to compute GDD for several sets of temperature data and compared the results. The first data set was hypothetical to ensure that various combinations of maximum, minimum, and base temperatures were tested. These temperatures were within commonly expected temperatures for winter wheat and corn in the central Great Plains. The second data set was collected at the Colorado State University Horticulture Farm in 1987 using a standard Class A weather station (McMaster et al., 1994). Daily maximum and minimum air temperatures were recorded at $2 \mathrm{~m}$ above the soil surface. Growing degree-days were calculated for the winter wheat growing season (September through July) and corn (April through October). The base temperature used for winter wheat was $0^{\circ} \mathrm{C}$ (McMaster and Smika, 1988) and for corn was $10^{\circ} \mathrm{C}$ (Cross and Zuber 1972).

Because GDD for corn normally are calculated using an upper temperature threshold $\left(T_{\mathrm{UT}}\right)$, we modified both methods to also incorporate $T_{\mathrm{UT}}$ to better assess differences between the two methods. We set $T_{\mathrm{UT}}$ equal to $30^{\circ} \mathrm{C}$ for corn (Cross and Zuber, 1972) and $25^{\circ} \mathrm{C}$ for wheat (McMaster and Smika, 1988). Upper threshold temperatures are incorporated into the GDD calculations using the following temperature adjustments before evaluating Eq. (1). Method 1: before entering temperature data into $\mathrm{Eq}$ (1), the average temperature $\left[\frac{\left(T_{\mathrm{MAX}}+T_{\mathrm{MIN}}\right)}{2}\right]$ is set equal to $T_{\mathrm{BASE}}$ if less than $T_{\mathrm{BASE}}$ and is set equal to $T_{\mathrm{UT}}$ when greater than $T_{\mathrm{UT}}$. Method 2: before entering temperature data into Eq. (1), $T_{\text {MAX }}$ and $T_{\text {MIN }}$ are set equal to $T_{\mathrm{BASE}}$ if less than $T_{\mathrm{BASE}}$ and are set equal to $T_{\mathrm{UT}}$ when greater than $T_{\mathrm{UT}}$.

\section{Results and discussion}

A hypothetical 10-day temperature data set illustrates how the methods differ in calculating GDD. A 


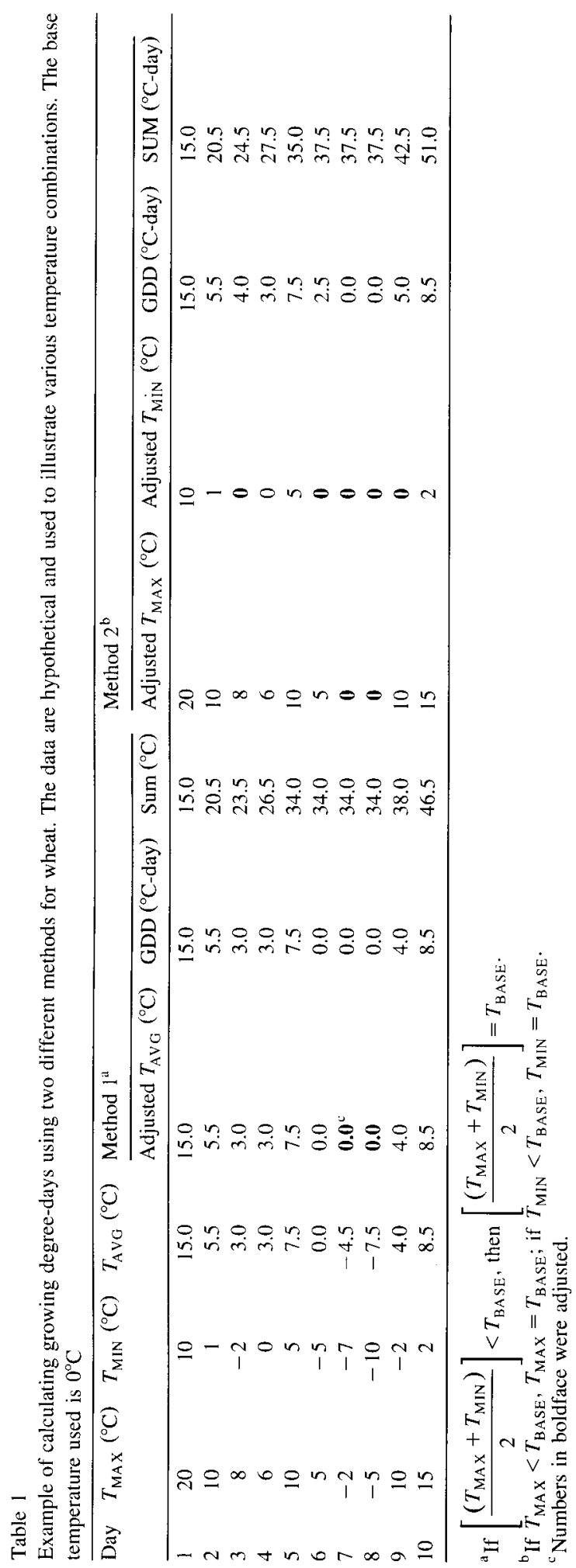


difference of 4.5 GDD, or about $10 \%$, occurred between the two methods when using $T_{\mathrm{BASE}}=0^{\circ} \mathrm{C}$ for wheat (Table 1). Graphical illustration of different estimates for the two methods is shown in Fig. 1. In situations where $T_{\mathrm{MAX}}$ and $T_{\mathrm{MIN}}$ exceed $T_{\mathrm{BASE}}$ (Fig. 1A) or $T_{\mathrm{MAX}}$ and $T_{\mathrm{MIN}}$ are less than $T_{\mathrm{BASE}}$ (Fig. 1C), both methods result in the same estimate of $T_{\mathrm{AVG}}$, and therefore estimate the same GDD (in the latter case). When $T_{\mathrm{MIN}}<T_{\mathrm{BASE}}<T_{\mathrm{MAX}}$, Method 2 estimates more GDD than Method 1 because the adjusted $T_{\mathrm{AVG}}$ is greater due to resetting $T_{\mathrm{MIN}}$ to $T_{\text {BASE }}$ (Fig. 1B).

With field data, much greater differences between the methods are observed. For wheat, the greatest difference occurred during February, with Method 2 having $83 \%$ (45 GDD) more thermal units than Method 1 (Table 2). Even greater differences between the methods were obtained for corn $\left(T_{\mathrm{BASE}}=\right.$ $10^{\circ} \mathrm{C}$ ), with the month of October having the greatest difference of $376 \%$ (94 GDD) between the methods (Table 3). When GDD were summed over the growing season, the two methods differed by 9 and $28 \%$ (254 and 326 GDD) for wheat and corn, respec- tively. Differences of this magnitude can be quite important.

Using wheat to illustrate the impact of the differences noted in the two interpretations of Eq. (1) and assuming that $T_{\mathrm{AVG}}$ is $18^{\circ} \mathrm{C}$ in June, then a cumulative difference of 254 GDD between the methods is equivalent to approximately 14 calendar days. Estimating maturity will therefore be in error by at least 14 days just due to the different methods of calculating GDD. Actually the error will probably be greater because most of the differences in the calculations occurred during months with much lower $T_{\mathrm{AVG}}$, and therefore even more calendar days are equivalent to 254 GDD. This suggests that predicting growth stages such as jointing will have greater error than for growth stages such as maturity.

Another way of assessing the importance of the difference defined in the previous paragraph between the methods is to realize that most of the difference resulted during the vegetative stage of development for winter wheat. If we assume a phyllochron, or rate of leaf appearance, of 105 GDD leaf ${ }^{-1}$ (McMaster and Wilhelm, 1995; McMaster et al., 1992a), then a

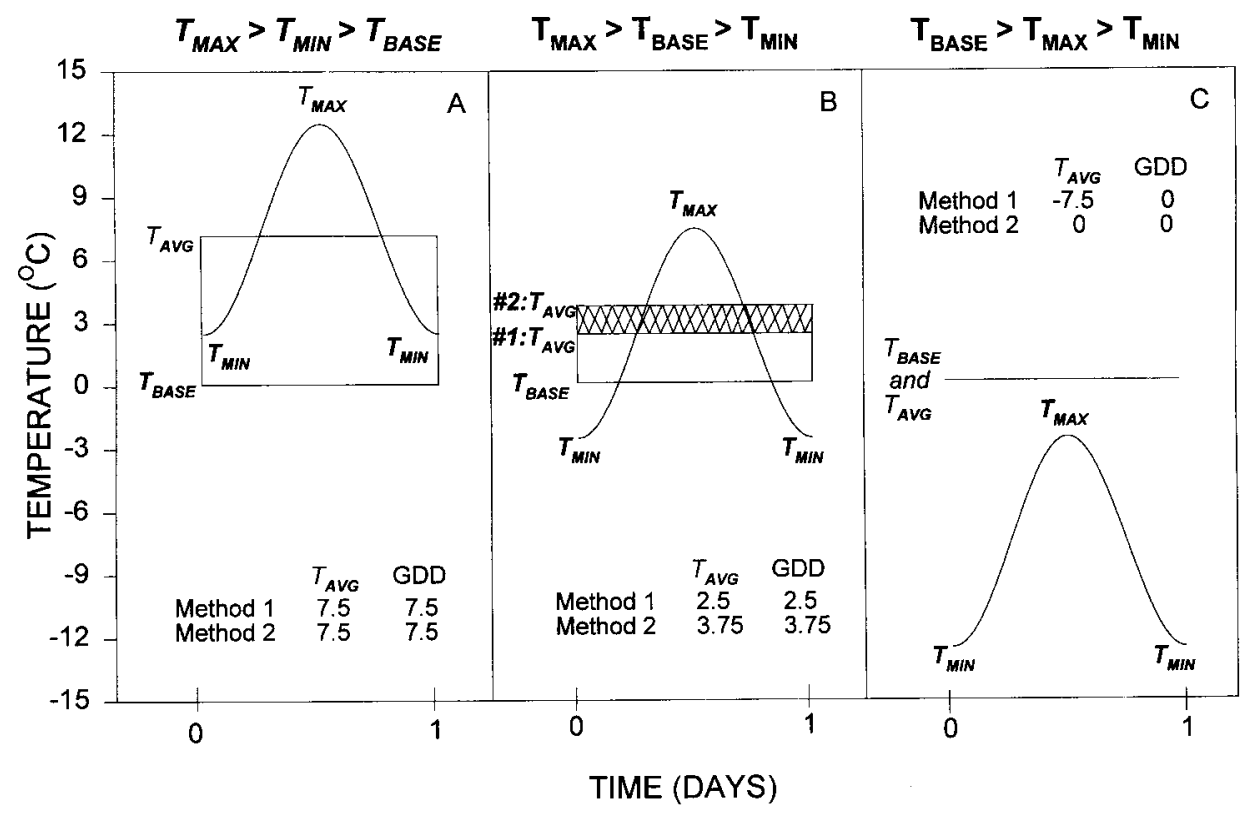

Fig. 1. Visual representation of the different integration areas by the two methods of calculating GDD for different conditions. For illustrative purposes, the diurnal temperature curve is represented as a sine curve. In these examples, (A) represents situations where $T_{\mathrm{MAX}}>T_{\mathrm{MIN}}>T_{\mathrm{BASE}}$, (B) represents conditions where $T_{\mathrm{MAX}}>T_{\mathrm{BASE}}>T_{\mathrm{MIN}}$, and (C) $T_{\mathrm{BASE}}>T_{\mathrm{MAX}}>T_{\mathrm{MIN}}$. The base temperature is $0^{\circ} \mathrm{C}$. The cross-hatched area in (B) denotes the difference estimated by the two methods. In (A) and (C) both methods estimate the same GDD. 
Table 2

Comparison of methods for winter wheat using 1987 weather data from Fort Collins, CO. Months are ordered from September, when winter wheat is normally planted, through July, when typically harvested

\begin{tabular}{|c|c|c|c|c|c|c|c|c|c|c|c|c|}
\hline \multirow[t]{3}{*}{ Month } & \multicolumn{6}{|l|}{ Base only } & \multicolumn{6}{|c|}{ Base and upper threshold ${ }^{b}$} \\
\hline & \multicolumn{3}{|l|}{ Interval } & \multicolumn{3}{|c|}{ From 1 September } & \multicolumn{3}{|l|}{ Interval } & \multicolumn{3}{|c|}{ From 1 September } \\
\hline & Method $1^{c}$ & Method $2^{d}$ & Diff. & Method 1 & Method 2 & Diff. & Method $1^{e}$ & Method $2^{f}$ & Diff. & Method 1 & Method 2 & Diff. \\
\hline & GDD & GDD & $\%$ & GDD & GDD & $\%$ & GDD & GDD & $\%$ & GDD & GDD & $\%$ \\
\hline Sep & 424 & 424 & 0 & 424 & 424 & 0 & 424 & 412 & -3 & 424 & 412 & -3 \\
\hline Oct & 240 & 279 & 16 & 664 & 703 & 6 & 240 & 278 & 16 & 664 & 690 & 4 \\
\hline Nov & 103 & 144 & 40 & 767 & 847 & 10 & 103 & 144 & 40 & 767 & 834 & 9 \\
\hline Dec & 0 & 3 & - & 767 & 850 & 11 & 0 & 3 & - & 767 & 837 & 9 \\
\hline Jan & 64 & 109 & 70 & 831 & 959 & 15 & 64 & 109 & 70 & 831 & 946 & 14 \\
\hline Feb & 54 & 99 & 83 & 885 & 1058 & 20 & 54 & 99 & 84 & 885 & 1045 & 18 \\
\hline Mar & 100 & 151 & 51 & 985 & 1209 & 23 & 100 & 151 & 51 & 985 & 1196 & 21 \\
\hline Apr & 276 & 306 & 11 & 1261 & 1515 & 20 & 276 & 301 & 9 & 1261 & 1497 & 19 \\
\hline May & 415 & 415 & 0 & 1676 & 1930 & 15 & 415 & 411 & -1 & 1676 & 1908 & 14 \\
\hline June & 553 & 553 & 0 & 2229 & 2483 & 11 & 553 & 511 & -8 & 2229 & 2419 & 9 \\
\hline July & 631 & 631 & 0 & 2860 & 3114 & 9 & 631 & 557 & -12 & 2860 & 2976 & 4 \\
\hline
\end{tabular}

${ }^{\text {atUsing }} T_{\text {BASE }}$ only $\left(0^{\circ} \mathrm{C}\right)$.

${ }^{\mathrm{b}}$ Using $T_{\mathrm{BASE}}\left(0^{\circ} \mathrm{C}\right)$ and an upper threshold $\left(25^{\circ} \mathrm{C}\right)$

${ }^{c}$ If $\left[\frac{\left(T_{\mathrm{MAX}}+T_{\mathrm{MIN}}\right)}{2}\right]<T_{B A S E}$, then $\left[\frac{\left(T_{\mathrm{MAX}}+T_{\mathrm{MIN}}\right)}{2}\right]=T_{\mathrm{BASE}}$.

${ }^{\mathrm{d}}$ If $T_{\mathrm{MAX}}<T_{\mathrm{BASE}}, T_{\mathrm{MAX}}=T_{\mathrm{BASF}} ;$ if $T_{\mathrm{MIN}}<T_{\mathrm{BASE}}, T_{\mathrm{MIN}}=T_{\mathrm{BASE}}$.

${ }^{\mathrm{e}}$ If $\left[\frac{\left(T_{\mathrm{MAX}}+T_{\mathrm{MIN}}\right)}{2}\right]<T_{\mathrm{BASE}}$, then $\left[\frac{\left(T_{\mathrm{MAX}}+T_{\mathrm{MIN}}\right)}{2}\right]=T_{\mathrm{BASE}}$; if $\left[\frac{\left(T_{\mathrm{MAX}}+T_{\mathrm{MIN}}\right)}{2}\right]>T_{\mathrm{UT}}$, then $\left[\frac{\left(T_{\mathrm{MAX}}+T_{\mathrm{MIN}}\right)}{2}\right]=T_{\mathrm{UT}}$.

${ }^{\mathrm{i}}$ If $T_{\mathrm{MAX}}<T_{\mathrm{BASE}}, T_{\mathrm{MAX}}=T_{\mathrm{BASE}}$; if $T_{\mathrm{MIN}}<T_{\mathrm{BASE}}, T_{\mathrm{MIN}}=T_{\mathrm{BASE}}$; if $T_{\mathrm{MAX}}>T_{\mathrm{UT}}, T_{\mathrm{MAX}}=T_{\mathrm{UT}}$; if $T_{\mathrm{MIN}}>T_{\mathrm{UT}}$, $T_{\mathrm{MIN}}=T_{\mathrm{UT}}$.

Table 3

Comparison of methods for corn using 1987 weather data from Fort Collins, CO. Months are ordered from April, when corn is normally planted, through October, when typically harvested

\begin{tabular}{|c|c|c|c|c|c|c|c|c|c|c|c|c|}
\hline \multirow[t]{3}{*}{ Month } & \multicolumn{6}{|l|}{ Base only } & \multicolumn{6}{|c|}{ Base and upper threshold ${ }^{b}$} \\
\hline & \multicolumn{3}{|l|}{ Interval } & \multicolumn{3}{|c|}{ From 1 April } & \multicolumn{3}{|l|}{ Interval } & \multicolumn{3}{|c|}{ From 1 April } \\
\hline & $\overline{\text { Method } \mathrm{I}^{\mathrm{c}}}$ & Method $2^{d}$ & Diff. & Method 1 & Method 2 & Diff. & Method $1^{e}$ & Method $2^{f}$ & Diff. & Method 1 & Method 2 & Diff. \\
\hline & GDD & GDD & $\%$ & GDD & GDD & $\%$ & GDD & GDD & $\%$ & GDD & GDD & $\%$ \\
\hline Apr & 58 & 138 & 138 & 58 & 138 & 138 & 54 & 133 & 146 & 54 & 133 & 146 \\
\hline May & 111 & 165 & 49 & 169 & 303 & 79 & 107 & 160 & 50 & 161 & 293 & 82 \\
\hline June & 253 & 264 & 4 & 422 & 567 & 34 & 211 & 221 & 5 & 372 & 514 & 38 \\
\hline July & 321 & 328 & 2 & 743 & 895 & 20 & 247 & 254 & 3 & 619 & 768 & 24 \\
\hline Aug & 257 & 268 & 4 & 1000 & 1163 & 16 & 222 & 233 & 5 & 841 & 1001 & 19 \\
\hline Sep & 129 & 198 & 53 & 1129 & 1361 & 21 & 117 & 186 & 59 & 958 & 1187 & 24 \\
\hline Oct & 25 & 119 & 376 & 1154 & 1480 & 28 & 24 & 117 & 388 & 982 & 1304 & 33 \\
\hline
\end{tabular}

${ }^{\mathrm{a}}$ Using $T_{\mathrm{BASE}}$ only $\left(10^{\circ} \mathrm{C}\right)$.

${ }^{\mathrm{b}}$ Using $T_{\mathrm{BASE}}\left(10^{\circ} \mathrm{C}\right)$ and an upper threshold $\left(30^{\circ} \mathrm{C}\right)$.

If $\left[\frac{\left(T_{\mathrm{MAX}}+T_{\mathrm{MIN}}\right)}{2}\right]<T_{\mathrm{BASE}}$, then $\left[\frac{\left(T_{\mathrm{MAX}}+T_{\mathrm{MIN}}\right)}{2}\right]=T_{\mathrm{BASE}}$.

${ }^{3}$ If $T_{\mathrm{MAX}}<T_{\mathrm{BASE}}, T_{\mathrm{MAX}}=T_{\mathrm{BASE}}$; if $T_{\mathrm{MIN}}<T_{\mathrm{BASE}}, T_{\mathrm{M} 1 \mathrm{~N}}=T_{\mathrm{BASE}}$.

${ }^{\mathrm{e}}$ If $\left[\frac{\left(T_{\mathrm{MAX}}+T_{\mathrm{MIN}}\right)}{2}\right]<T_{\mathrm{BASE}}$, then $\left[\frac{\left(T_{\mathrm{MAX}}+T_{\mathrm{MIN}}\right)}{2}\right]=T_{\mathrm{BASE}}$; if $\left[\frac{\left(T_{\mathrm{MAX}}+T_{\mathrm{MIN}}\right)}{2}\right]>T_{\mathrm{UT}}$, then $\left[\frac{\left(T_{\mathrm{MAX}}+T_{\mathrm{MIN}}\right)}{2}\right]=T_{\mathrm{UT}}$.

${ }^{\mathrm{f}}$ If $T_{\mathrm{MAX}}<T_{\mathrm{BASE}}, T_{\mathrm{MAX}}=T_{\mathrm{BASE}}$; if $T_{\mathrm{MIN}}<T_{\mathrm{BASE}}, T_{\mathrm{MIN}}=T_{\mathrm{BASE}}$; if $T_{\mathrm{MAX}}>T_{\mathrm{UT}}, T_{\mathrm{MAX}}=T_{\mathrm{UT}}$; if $T_{\mathrm{MIN}}>T_{\mathrm{UT}}, T_{\mathrm{MIN}}=T_{\mathrm{UT}}$. 


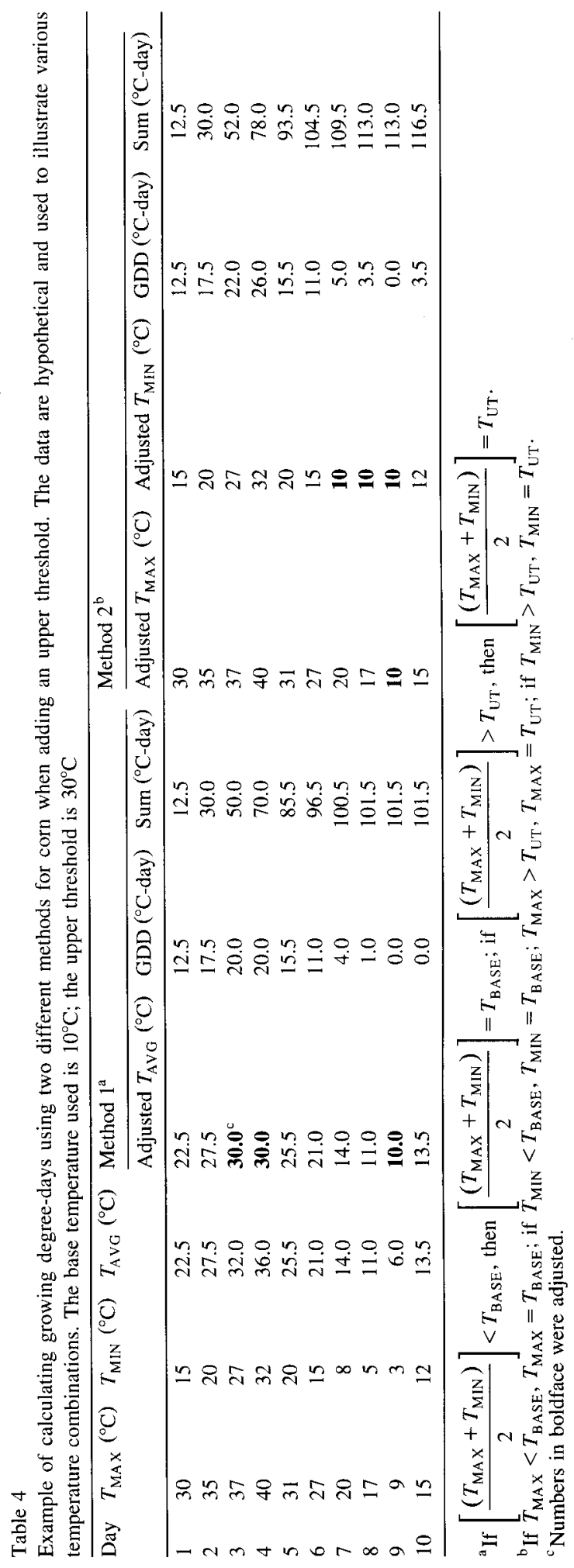


difference of about 2.4 leaves would be predicted based on the difference between methods. In simulation models such as MODWht (Rickman et al., 1995) and SHOOTGRO (McMaster et al., 1992a; Wilhelm et al., 1993), or conceptual models of development (e.g., Klepper et al., 1984), where phenological development is closely integrated using the phyllochron, errors of 2.4 leaves are significant in predicting the timing of events, canopy development, and other processes.

These results suggest that differences of well over $50 \%$ can occur between the two methods of calculating GDD. As a result, estimating GDD by one method and applying the estimate to an algorithm parameterized by the other method results in unnecessary errors. The magnitude of the error is entirely dependent on the temperature data used to calculate GDD. If $T_{\text {MIN }}$ is never less than $T_{\text {BASE }}$, the methods produce identical results (Fig. IA; Table 1, days 1, 2, 5 , and 10). However, this is rarely, if ever, encountered in field situations. When only $T_{\mathrm{MIN}}$ is less than $T_{\text {BASE }}$, Method 1 will calculate fewer GDD than Method 2 (Fig. 1B; Table 1, days 3, 6, and 9). This situation occurs when temperatures are normally near $T_{\text {BASE}}$. For winter wheat in Colorado, this is late fall and winter and early spring (Table 2 ). For corn, this is spring and late fall (Table 3 ). When both $T_{\text {MAX }}$ and $T_{\text {MIN }}$ are less than $T_{\mathrm{BASE}}$, again both methods will calculate the same GDD (Fig. 1C; Table 1, days 7 and 8). For winter wheat, this occurs during winter; for corn it occasionally occurs in late spring and early fall. Changing the base temperature does not resolve the problem, it only changes the timing of the difference between methods.

When an upper threshold is incorporated into the GDD calculations, as is normally done for crops such as corn (e.g., Cross and Zuber, 1972; Gilmore and Rogers, 1958; Russelle et al., 1984), significant differences continue to result between the two methods. An upper threshold is incorporated into the calculation the same way as the base temperature, except that either $T_{\mathrm{AVG}}, T_{\mathrm{MAX}}$, or $T_{\mathrm{MIN}}$ are reset to $T_{\text {UT }}$ whenever they exceed $T_{\text {UT }}$ (Table 4 ). For corn, the upper threshold is typically set to $30^{\circ} \mathrm{C}$ (Cross and Zuber, 1972; Russelle et al., 1984). With the incorporation of an upper threshold, the differences in GDD calculated between the two methods is slightly greater than when using only a base tempera- ture for corn (Table 3) and slightly less for wheat when using a $25^{\circ} \mathrm{C}$ upper threshold (Table 2). Even when differences between methods were decreased when adding an upper threshold, the differences remained large. In the situation where $T_{\mathrm{MAX}}>T_{\mathrm{UT}}$ $>T_{\text {MIN }}$, Method 1 estimates more GDD than Method 2 , the opposite of when $T_{\mathrm{MIN}}<T_{\mathrm{BASE}}<T_{\mathrm{MAX}}$ (Fig. 1B) where Method 1 estimates fewer GDD than Method 2. Therefore, when summing GDD over a growing season, differences in methods may negate each other. However, daily estimate differences will still exist.

The GDD approach is often used in crop models (e.g., Baker and Landivar, 1991; Kiniry and Bonhomme, 1991; Rickman et al., 1995; Weir et al., 1984; Wilhelm et al., 1993; Williams et al., 1989). Both methods of calculating GDD are used in crop models, and to be certain of the method used, one must examine the code because documentation is usually not clear. To avoid unnecessary error, the methods used in calculating GDD in the model must agree with the values used to parameterize the model. Because models are usually parameterized from literature data and the literature usually does not specify which method was used to calculate GDD, it is likely that the problem we identified is common in models.

Given there are two interpretations for calculating GDD, it is tempting to suggest a standard. We have several problems with doing this. First, we do not feel either method is more correct. In fact, both methods ere only approximations for the true GDD (Anold, 1960). Second, both methods are, and have been, widely used. In essentially all cases, it is not possible to recalculate the GDD because it is either not known which method was used, or the data are not available, or both. Third, the decision to create a standard would best be made by a group composed of individuals with diverse experiences in crop research and management and the standard may need to better approximate the true GDD value (Pruess, 1983; Zalom et al., 1983).

\section{Conclusion}

There are two implementations of the basic GDD equation: $\mathrm{GDD}=\left[\frac{\left(T_{\mathrm{MAX}}+T_{\mathrm{MIN}}\right)}{2}\right]-T_{\mathrm{BASE}}$ in 
wide-spread use today. These implementations result in different GDD estimates. Therefore, we strongly urge authors to precisely describe the method of calculating GDD in their papers. By clearly defining the method used to compute GDD, research results can be interpreted and applied correctly by others.

\section{References}

Allen, J.C., 1976. A modified sine wave method for calculating degree days. Environ. Ent. 5, 388-396.

Arnold, C.Y., 1960. Maximum-minimum temperatures as a basis for computing heat units. Proc. Am. Soc. Hort. Sci. 76, 292-682.

Baker, D.N., Landivar, J.A., 1991. The simulation of plant development in GOSSYM. In: Hodges, T. (Ed.), Predicting Crop Phenology. CRC Press, Boca Raton, FL, USA, pp. 171-180.

Baker, J.T., Pinter, P.J. Jr., Reginato, R.J., Kanemasu, E.T., 1986. Effects of temperature on leaf appearance in spring and winter wheat cultivars. Agron. J. 78, 605-613.

Bauer, A., Garcia, R., Kanemasu, E.T., Blad, B.L., Hatfield, J.L., Major, D.J., Reginato, R.J., Hubbard, K.G., 1988. Effect of latitude on phenology of Colt winter wheat. Agric. For. Meteorol. 44, 131-140.

Cross, H.Z., Zuber, M.S., 1972. Prediction of flowering dates in maize based on different methods of estimating thermal units. Agron. J. 64, 351-355.

Cutforth, H.W., Shaykewich, C.F., 1989. Relationship of development rates of corn from planting to silking to air and soil temperature and to accumulated thermal units in a prairie environment. Can. J. Plant Sci. 69, 121-132.

Davidson, H.R., Campbell, C.A., 1983. The effect of temperature, moisture and nitrogen on the rate of development of spring wheat as measured by degree days. Can. J. Plant Sci. 63, 833-846.

DeGaetano, A.T., Knapp, W.W., 1993. Standardization of weekly growing degree day accumulations based on differences in temperature observation time and method. Agric. For. Meteorol. $66,1-19$.

Edwardson, S.E., Watt, D.L., 1987. GROWTH STAGE: Using growing degree days to predict the Haun scale of spring wheat. Appl. Agric. Res. 2, 224-229.

Gallagher, J.N., 1979. Field studies of cereal leaf growth: I. Initiation and expansion in relation to temperature and ontogeny. J. Exp. Bot. 30, 625-636.

Gilmore, E.C. Jr., Rogers, J.S., 1958. Heat units as a method of measuring maturity in corn. Agron. J. 50, 611-615.

Goyne, P.J., Woodruff, D.R., Churchett, J.D., 1977. Prediction of flowering in sunflowers. Aust. J. Exp. Agric. Anim. Husb. 17, $475-481$.

Jefferies, R.A., Mackerron, D.K.L., 1987. Thermal time as a non-destructive method of estimating tuber initiation in potatoes. J. Agric. Sci., Camb. 108, 249-252.

Ketring, D.L., Wheless, T.G., 1989. Thermal time requirements for phenological development of peanut. Agron. J. 81, 910917.

Kiniry, J.R., Bonhomme, R., 1991. Predicting maize phenology. In: Hodges, T. (Ed.), Predicting Crop Phenology. CRC Press, Boca Raton, FL, USA, pp. 115-132.

Kirby, E.J.M., 1995. Factors affecting rate of leaf emergence in barley and wheat. Crop Sci. 35, 11-19.

Klepper, B., Belford, R.K., Rickman, R.W., 1984. Root and shoot development in winter wheat. Agron. J. 76, 117-122.

Masle, J., Doussinalut, G., Farquhar, G.D., Sun, B., 1989. Foliar stage in wheat correlates better to photothermal time than to thermal time. Plant, Cell Environ. 12, 235-247.

Masoni, A., Ercoli, L., Massantini, F., 1990. Relationship between number of days, growing degree days and photothermal units and growth in wheat (Triticum aesticum L.) according to seeding time. Agric. Med. 120, 41 $\sim 51$.

Mathan, K.K., 1989. Influence of accumulated heat units and sunshine hours on the growth and yield of sorghum (var. Co 25). J. Agron. and Crop Sci. 163, 196-200.

McMaster, G.S., 1993. Another wheat (Triticum spp.) model? Progress and applications in crop modeling. Rivista di Agronomia 27, 264-272.

McMaster, G.S., Smika, D.E., 1988. Estimation and evaluation of winter wheat phenology in the central Great Plains. Agric. For. Meteorol. 43, 1-18.

McMaster, G.S., Wilhelm, W.W., 1995. Accuracy of equations predicting the phyllochron of wheat. Crop Sci. 35, 30-36.

McMaster, G.S., Wilhelm, W.W., 1997. Conservation compliance credit for winter wheat fall biomass production and implications for grain yield. J. Soil Water Conserv., 52.

McMaster, G.S., Morgan, J.A., Wilhelm, W.W., 1992a. Simulating winter wheat spike development and growth. Agric. For. Meteorol. 60, 193-220.

McMaster, G.S., Wilhelm, W.W., Morgan, J.A., 1992b. Simulating winter wheat shoot apex phenology. J. Agric. Sci., Camb. $119,1-12$.

McMaster, G.S., Wilhelm, W.W., Bartling, P.N.S., 1994. Irrigation and culm contribution to yield and yield components of winter wheat. Agron. J. 86, 1123-1127.

Narwal, S.S., Poonia, S., Singh, G., Malik, D.S., 1986. Influence of sowing dates on the growing degree days and phenology of winter maize (Zea mays L.). Agric. For. Meteorol. 38, 47-57.

Nield, R.E., Seeley, M.W., 1977. Growing degree days predictions for corn and sorghum development and some applications to crop production in Nebraska. Nebr. Agric. Exp. Stn. Res. Bull. 280. Lincoln, NE.

Nuttonson, M.Y., 1948. Some preliminary observations of phenological data as a tool in the study of photoperiodic and thermal requirements of various plant material. In: Murneed, A.E., Whyte, R.D. (Eds.), Vernalization and Photoperiodism-A Symposium. Chronica Botanica Pub., Waltham, MA.

Perry, K.B., Wehner, T.C., Johnson, G.L., 1986. Comparison of 14 methods to determine heat unit requirements for cucumber harvest. Hort. Sci. 21, 419-423.

Pruess, K.P., 1983. Day-degree methods for pest management. Environ. Ent. 12, 613-619.

Rickman, R.W., Waldman, S., Klepper, B.L., 1995. MODWht: 
development driven winter wheat growth simulation. Agron. J. 87.

Russelle, M.P., Wilhelm, W.W., Otson, R.A., Power, J.F., 1984. Growth analysis based on degree days. Crop Sci. 24, 28-32.

Swanson, S.P., Wilhelm, W.W., 1996. Planting date and residue rate effects on growth, partitioning, and yield of corn. Agron. J. 88.

Tollenaar, M., Daynard, T.B., Hunter, R.B., 1979. Effect of temperature on rate of leaf appearance and flowering date in maize. Crop Sci. 19, 363-366.

Wang, J.Y., 1960. A critique of the heat unit approach to plant response studies. Ecology 41, 785-790.

Weir, A.H., Bragg, P.L., Porter, J.R., Rayner, J.H., 1984. A winter wheat crop simulation model without water or nutrient limitations. J. Agric. Sci., Camb. 102, 371-382.

Wilhelm, W.W., McMaster, G.S., 1995. The importance of the phyllochron in studying the development of grasses. Crop Sci. $35,1-3$.

Wilhelm, W.W., Schepers, L.N., Mielke, J.S., Doran, J.W., Ellis,
J.R., Stroup, W.W., 1987. Dryland maize development and yield resulting from tillage and nitrogen fertilization practices. Soil Tillage Res. 10, 167-179.

Wilhelm, W.W., Bouzerzour, H., Power, J.F., 1989. Soil disturbance-residue management effect on winter wheat growth and yield. Agron. J. 81, 581-588.

Wilhelm, W.W., McMaster, G.S., Rickman, R.W., Klepper, B., 1993. Above ground vegetative development and growth of winter wheat as influenced by nitrogen and water availability. Ecol. Model 68, 183-203.

Williams, J.R., Jones, C.A., Kiniry, J.R., Spanel, D.A., 1989. The EPIC crop growth model. Trans. Am. Soc. Agric. Eng. 32, 497-511.

Zalom, F.G., Goodell, P.B., Wilson, L.T., Barnett, W.W., Bentley. W.J., 1983. Degree-days: the calculation and use of heat units in pest management. Leaflet No.21373, Division of Agriculture and Natural Resources, University of California, Berkeley, CA, 94720. 